\title{
Ripple Effects of Surface Acting: A Diary Study among Dual-Earner Couples
}

\author{
Arnold B. Bakker1, Ana Isabel Sanz-Vergel², Alfredo Rodríguez-Muñoz ${ }^{3}$ and Mirko Antino ${ }^{3}$ \\ ${ }^{1}$ Erasmus University Rotterdam (The Netherlands) \\ ${ }^{2}$ University of East Anglia (UK) \\ ${ }^{3}$ Universidad Complutense (Spain)
}

\begin{abstract}
This study among 80 dual-earner couples examines the ripple effects of emotional labour - on a daily basis. Specifically, we propose that employees who engage in surface acting at work drain their energetic resources, and undermine their own relationship satisfaction. Drawing upon conservation of resources (COR) theory, we predicted that work-related exhaustion would mediate the relationship between surface acting at work and at home. In addition, we hypothesized that employees' emotional energy in the evening would mediate the relationship between surface acting at home and (actor and partner) satisfaction with the relationship. Participants filled in a survey and a diary booklet during five consecutive working days ( $N=80$ couples, $N=160$ participants $x 5$ days, $N=800$ occasions). The hypotheses were tested with multilevel analyses, using the actor-partner interdependence model. Results showed that daily workrelated exhaustion partially mediated the relationship between daily surface acting at work and at home. As hypothesized, daily surface acting at home influenced own and partner's daily relationship satisfaction through reduced daily emotional energy. These findings offer support for COR theory, and have important implications for organizations that encourage emotion regulation.
\end{abstract}

Received 5 May 2018; Revised 26 November 2018; Accepted 29 November 2018

Keywords: diary research, satisfaction, spillover-crossover, surface acting.

Researchers and managers have become more interested in the concept of emotional labor since the services sector has become a crucial part of the global economy (Grandey, 2000; Grandey \& Gabriel, 2015). In this work environment, one of the key employee requirements, implicit or explicit, is to effectively manage affective experiences at work. Specifically, service employees are expected to display positive emotions and suppress negative ones in their daily interactions with customers. Emotional labor is defined as "the effort, planning, and control needed to express organizationally desired emotion during interpersonal transactions" (Hochschild, 1983, p. 987). Research has revealed that there are two main types of emotional labor. Deep acting refers to the modification of actual feelings in order to feel the appropriate emotions given a situation, whereas surface acting refers to suppressing, amplifying, or faking emotions without making any effort to change what one is actually feeling. Research suggests that deep acting is associated with positive outcomes such as better service performance (Totterdell \& Holman, 2003), whereas surface acting is associated with negative outcomes, such as job burnout or exhaustion

Correspondence concerning this article should be addressed to Alfredo Rodríguez-Muñoz. Departamento de Psicología Social, del Trabajo y Diferencial de la Universidad Complutense. 28040 Madrid (Spain).

E-mail: alfredo.rodriguez@psi.ucm.es
(Martínez-Íñigo, Totterdell, Alcover, \& Holman, 2007). Due to its detrimental impact, in the present study, we decided to focus our attention on surface acting at work. We investigate how surface acting triggers a loss spiral of energy resources and affects employees and their partner on a daily basis.

So far, little is known about whether and how emotional labor may have an impact in the non-work domain. To address this gap in the literature, a recent line of research has focused on emotional labor experiences at home (Montgomery, Panagopolou, \& Benos, 2005; Sanz-Vergel, Rodríguez-Muñoz, Bakker, \& Demerouti, 2012; Yanchus, Eby, Lance, \& Drollinger, 2010). These studies have focused on antecedents of emotional labor within the same domain (e.g., how frequency of emotions at home affects surface acting at home), or on consequences of emotional labor at home (mainly well-being), but not on the interplay between domains or on possible mechanisms explaining the spillover. A better understanding of the dynamics between work and home is crucial to help employees maintain their overall well-being.

How to cite this article:

Baker, A. B., Sanz-Vergel, A. I., Rodríguez-Muñoz, A., \& Antino, M. (2018). Ripple effects of surface acting: A diary study among dual-earner couples. The Spanish Journal of Psychology, 22. e7. Doi:10.1017/sjp.2019.6 
Therefore, there are two important gaps in the literature that we address in this study. We examine (a) the underlying mechanism explaining the spillover of surface acting from the work to the home domain, and (b) the underlying mechanism explaining why surface acting at home affects satisfaction with the relationship, as reported by the employee and their partner (crossover effect). Specifically, we focus on "energy levels" as explanatory mechanism, and examine the mediating role of exhaustion in the relationship between surface acting at work and at home, and the mediating role of emotional energy in the relationship between surface acting at home and satisfaction with the relationship. The analysis of this sequence will help us understand why surface acting is used in different life domains, and why it may affect not only employees but also their partner.

Emotional labor has been defined as a dynamic process wherein emotion regulation strategies and its consequences may vary between and within individuals (Judge, Woolf, \& Hurst, 2009). For that reason, the current study used a daily diary approach to examine within-person and within-couples variation. The ActorPartner Interdependence Model (APIM) developed by Kenny, Kashy and Cook (2006) is an appropriate strategy of analysis when working with dyads, because different effects can be tested. For instance, Member A's predictor variable can be related to the own criterion variable (which is called an actor effect), but at the same time, it may have an impact on Member B (which is called a partner effect).

\section{Theoretical Background and Hypotheses}

As mentioned above, surface acting is one of the core emotional labor dimensions. Grandey (2003) refers to surface acting as a strategy consisting of modifying displays without shaping inner feelings. She gives as an example an employee showing a sympathetic face when actually feeling irritated. Therefore, surface acting is mainly about showing "positive emotions" when the person does not actually feel them. Rafaeli and Sutton (1987) referred to surface acting as "faking in bad faith". Yanchus et al. (2010) went one step further and pointed out that this emotion regulation strategy can also be used in the home domain. Individuals are expected to engage in different family roles (e.g., supportive spouse, caring parent) as well as to perform various activities at home (e.g., cooking, playing with children) even when they are physically or emotionally drained. As in the work domain, surface acting at home involves showing empathy, understanding or happiness although one actually feels indifferent or bad.

Thus far, there are few studies that examined the interplay of work and family life in their analysis of surface acting. Two studies show that there is a clear positive relationship between surface acting at work and at home (Montgomery et al., 2005; Sanz-Vergel et al., 2012). In addition, Yanchus et al. (2010) demonstrated how frequency, variety, and intensity of emotions at work and at home led to surface acting at work and at home respectively, which in turn led to negative outcomes such as depression.

Such studies have only scratched the surface regarding what triggers surface acting at home and the mechanisms explaining the spillover and crossover of surface acting. Spillover refers to a within-person process that takes place across different life domains. That is, the feelings, cognitions, or behaviors expressed by an employee in the work domain are transferred to the non-work domain (Demerouti, Bakker, \& Schaufeli, 2005). In contrast, crossover involves transmission across individuals, whereby demands and their consequent strain cross over between closely related persons (Westman, 2001). In the present study, we examine the underlying mechanism explaining these two processes (see Figure 1).

\section{The spillover of surface acting: The mediating role of work-related exhaustion}

Existing research has focused on how reactions experienced in the work domain are transferred to and interfere with the non-work domain for the same individual (e.g., Ilies, Nahrgang, \& Morgeson, 2007). For example, individuals who feel unfairly treated at work are more likely to engage in negative interactions at home (Hoobler \& Brass, 2006). Thus, the experiences one individual has within an organizational setting may be good predictors of his/her experiences and behaviors in the personal domain. According to Edwards and Rothbard (2000), moods, values, skills, and behaviors can be directly transferred from the work domain to the home domain, which is known as a spillover effect.

Previous studies have found evidence for a spillover effect of surface acting. It has been shown that when people use this emotion regulation strategy to deal with others at work, they are likely to use the same strategy at home not only on a general basis (Montgomery et al., 2005) but also on a daily basis (Sanz-Vergel et al., 2012). However, the mechanism explaining why this spillover effect takes place has not been previously investigated. In the present study, we propose that work-related exhaustion will explain this link. Theoretically, what happens is know as a "loss spiral of resources". According to conservation of resources (COR) theory (Hobfoll, 1998, 2001), people are generally motivated to conserve their physical and psychological resources. Resources are those entities that are either centrally valued in their own right (e.g., self-esteem, energy, health) or act as a means to obtain centrally valued 


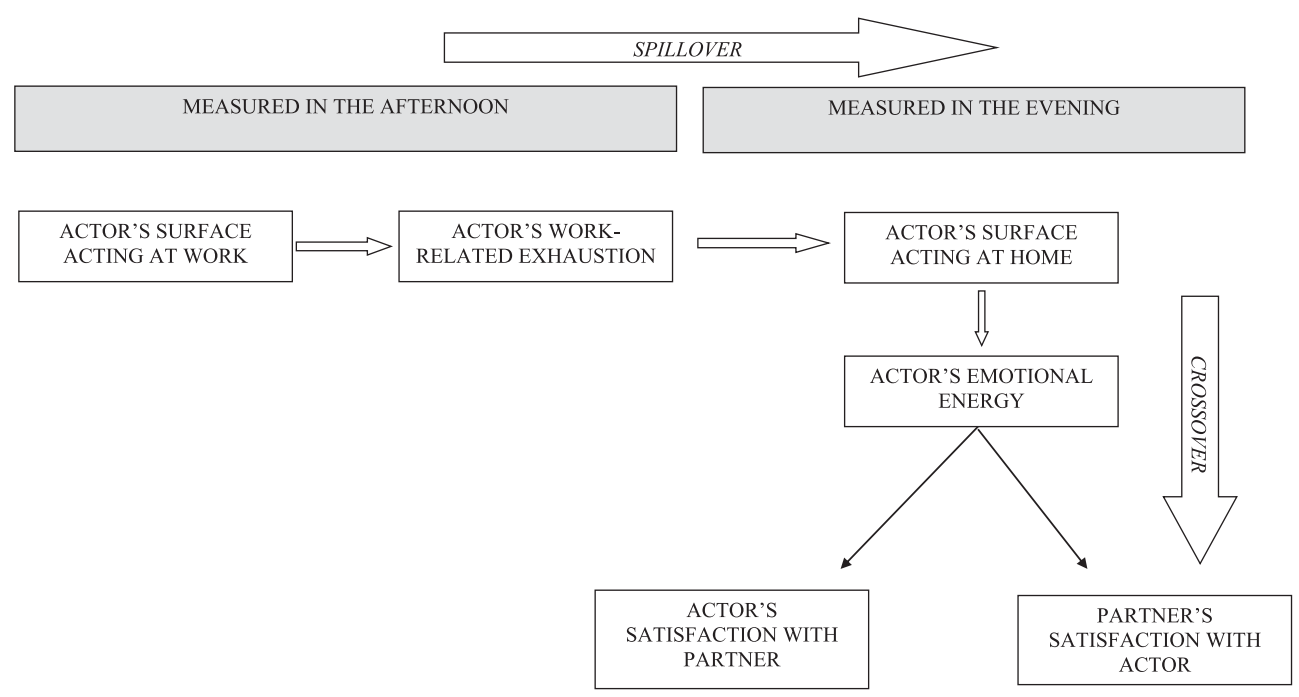

Figure 1. Theoretical Model of the Study and Variables.

ends (e.g., money, social support). In our study, we specifically refer to "energy" (i.e., work-related exhaustion and emotional energy) as a resource to deal with emotional requirements. COR researchers have conceptualized energy as a scarce resource, which must be immediately replenished when depleted (Hobfoll \& Shirom, 2001), since it is a finite resource in its availability.

COR theory proposes that "individuals strive to obtain, retain, protect and foster those things that they value" (Hobfoll, 2001, p. 341). Resources are valued because they help individuals deal with stressors, and because having resources helps to gain more resources. Events that result in a loss of resources are predicted to create stress and strain outcomes (Hobfoll, 1998). One important problem is that those with fewer resources are less capable of resource gain (Corollary 1), and that an initial loss begets future loss (Corollary 2). This means that people can end up in a loss spiral of resources (Hobfoll, 2001, p. 354). Evidence for this theory has been found in several life domains, including work and private relationships (e.g., Halbesleben, Harvey, \& Bolino, 2009).

In the present study, we use COR-theory to argue that surface acting is an emotional labor strategy that consumes considerable energetic resources. Indeed, it has been found that surface acting (not deep acting) was predictive of exhaustion and impaired performance (Hülsheger \& Schewe, 2011). Surface acting also involves a greater investment of resources than deep acting in the long term (Philipp \& Schüpbach, 2010). Daily surface acting at work will thus be positively related to exhaustion. Moreover, the initial loss of energy resources will lead to further loss, because employees who are more exhausted at the end of the workday, will be more likely to choose the emotion regulation strategy at home that seems easiest. Take as an example a doctor who has been dealing with difficult patients at work and has used surface acting as a strategy to deal with the patients. This person has made an effort trying to show positive emotions such as empathy or calmness without modifying his inner feelings (e.g., tiredness or irritation). As a result, this person will be exhausted when going home. However, once he is at home, and despite the fact that he is exhausted, he has to deal with family emotional requirements (e.g., listen to his partner's problems, playing with the children showing enthusiasm). The use of more elaborated emotional regulation strategies such as deep acting would require an investment of resources that this doctor does not have available. Therefore, to display the required emotions at home and adjust to family expectations, he will use surface acting also in this domain. Thus, we hypothesize that:

Hypothesis 1: Daily work-related exhaustion will mediate the relationship between daily surface acting at work and surface acting at home.

Surface acting at home and satisfaction with the relationship: The mediating role of emotional energy

Research has consistently shown that surface acting has negative consequences. For example, surface acting at work has been related to negative affective responses to work and to work-family conflict, whereas surface acting at home has been related to negative affective responses to family and to family-work conflict (Montgomery et al. 2005; Yanchus et al., 2010). Although surface acting is a strategy directed to others, prior research on emotional labor has not systematically examined its effects on customers and family. There is 
just little empirical evidence on the negative impact of surface acting at work on customer satisfaction (e.g., Hennig-Thurau, Groth, Paul, \& Gremler, 2006) and on the impact of surface acting at home on partner's surface acting at home (Sanz-Vergel et al., 2012).

In the present study, we follow our argument of loss spirals and propose that a lack of emotional energy will mediate the relationship between surface acting at home and relationship satisfaction (as reported by both members of the couple). We have included a measure of well-being that captures the level of energy people have in order to interact with others (Shirom, 2004), and have formulated the items as context-free. As suggested by Hobfoll (2001), each loss results in a depletion of resources for confronting the next threat, so an initial loss of energy resources may lead to future losses. We argued that surface acting at work would lead to surface acting at home via exhaustion, and in our second and third hypotheses we propose that the resource loss continues in the form of reduced emotional energy in the evening, which in turn reduces employees' and partner's satisfaction with the relationship (see Figure 1).

Continuing with the example of the doctor who faked emotions at home because he was exhausted, we argue that the few resources that the doctor could have available will have drained after faking also at home and he will not have much emotional energy left to engage in satisfactory interactions with the partner. This in turn will affect the relationship satisfaction of both members of the couple. That is, the doctor will not really enjoy interacting with his partner because he does not have the energy to engage in social activities, and his partner will not like the fact that the doctor is not investing energy in family life. Therefore, apart from examining within-person effects, we also predict a crossover effect, that is, how employee well-being affects partner's satisfaction. According to Westman (2001), crossover occurs when stress or strain, experienced by one person affects the level of stress or strain of another person in the same social environment. Scholars have found evidence for the crossover of other well-being indicators such as life satisfaction and work engagement (Demerouti et al., 2005). In the field of emotional labor, Yanchus et al. (2010) have suggested that using surface acting at home triggers negative emotional reactions in family life, but crossover effects have not been examined yet. Thus, this is the first study examining how surface acting at home and the consequent experienced strain crosses over in the form of reduced relationship satisfaction. Thus, we propose:

Hypothesis 2: Daily emotional energy mediates the relationship between daily surface acting at home and one's own daily relationship satisfaction
Hypothesis 3: Daily emotional energy mediates the relationship between daily surface acting at home and partner's daily relationship satisfaction.

\section{Method}

\section{Procedure and Sample}

We collected data from employees working in 25 different organizations during November-December 2012. To obtain access to employee samples, students from an introductory course in Organizational Psychology were asked to contact at least one employee who was willing to participate voluntarily in our study. The use of student contacts to obtain access to employee samples is quite common in organizational behavior literature (e.g., Demerouti \& Rispens, 2014). They were asked to contact at least one employee and his/her partner who were willing to participate voluntarily in our study. They met face-to-face with each participant and were responsible for the daily follow-up of their participants. In addition, they sent them daily reminders to fill out the questionnaires. Students received extra credit and a certificate of their collaboration in the study. Participants had to first fill in a short general questionnaire followed by a diary survey to be completed twice a day during five consecutive working days (Monday-Friday). Specifically, surface acting at work and work-related exhaustion were measured at the end of the workday (in the afternoon), whereas daily surface acting at home, emotional energy and relationship satisfaction were reported before going to bed (in the evening). For data collection, we used paper booklets. Responses of partners were linked by means of anonymous codes provided by the participants.

We distributed 220 survey packages and 181 questionnaires were returned ( $82.2 \%$ response rate). Of these, 21 questionnaires were excluded because information of at least one day was missing or participants did not complete the surveys at the appropriate time. The final sample was composed of eighty couples $(N=160$ participants $x 5$ days, $N=800$ occasions). We only included employees whose main work activity consisted of interacting with people, including colleagues, customers or subordinates. An analysis of their jobs revealed that most of the participants were working in the following sectors; health $(20.7 \%)$, industry $(12.7 \%)$, restaurants $(11.5 \%)$, trade $(9.6 \%)$, education $(8.3 \%)$, construction $(7 \%)$, transport $(7 \%)$, and financial institutions $(6.3 \%)$. Both members of the couple were employed and were living together. A prerequisite to participate was to spend at least one hour with the partner after work.

The final study sample included 80 men (50\%) and 80 women $(50 \%)$. The average age of the participants was 41.63 years $(S D=12.16)$ and their mean organizational tenure was 19.47 years $(S D=11.50)$. On average, 
they worked 39.17 hours per week $(S D=10.58)$. The majority of the couples $(69.7 \%)$ had at least one child, while $35 \%$ of the sample had a university degree or postgraduate studies. Most of them were salaried $(82.8 \%)$ and $34.4 \%$ of the sample had a supervisory position.

\section{Measures}

Surface acting at work and at home. We used the subscale from the Emotional Labor Scale (Brotheridge \& Lee, 2003). Items were slightly modified to measure surface acting at home ("Today at home" instead of "Today at work"). Items were rated on a 6-point scale, ranging from $1=$ not true at all to $6=$ totally true, (e.g., "Today at work/home, I have hidden my true feelings about a situation"). The mean Cronbach's alpha across the five occasions was .80 for surface acting at work and .79 for surface acting at home.

Work-related exhaustion was assessed with three items from the Shirom-Melamed Burnout Measure (SMBM, Shirom \& Melamed, 2006). Respondents had to report whether they had recently experienced energetic feelings at work (e.g., "Today at work, I felt physically drained"). Items were rated on a 6-point scale, ranging from $1=$ not true at all to $6=$ totally true. The mean of Cronbach's alphas across the five occasions was .77.

Emotional energy was measured with three items of the Shirom-Melamed Vigor Measure as a way of conceptualizing well-being (Shirom, 2004). An example item was "At this moment I feel able to show warmth to others"). Items were rated on a 6-point scale, ranging from $1=$ not true at all to $6=$ totally true. The mean of Cronbach's alpha across the five occasions was .86 .

Relationship satisfaction. Our measure of daily satisfaction with the relationship was based on Kunin (1955). It was measured using a single item at the end of the day (evening questionnaire): "Today, how satisfied are you with your partner/personal relationship?" We used faces as response options. The scale consists of five faces, ranging from "very unsatisfied" to "very satisfied". A oneitem measure of affective states is commonly used in diary designs (e.g., Fisher, Matthews \& Gibbons, 2016). For clarity purposes and to avoid redundancy of terms (partner satisfaction with the partner), in the manuscript we refer to "relationship satisfaction".

\section{Strategy of Analysis}

Due to the nested data structure; days (Level 1; $N=800$ observations), nested in persons (Level 2; $N=160$ participants), nested in couples (Level 3; $N=80$ dyads), we applied multilevel modeling using the MLwiN software (Rasbash, Browne, Healy, Cameron, \& Charlton, 2002). Following the methodological recommendations regarding diary studies, we centered person-level variables at the grand mean and day-level variables at the respective person mean (Ohly, Sonnentag, Niessen, \& Zapf, 2010). We analyzed our data following the actorpartner interdependence model (APIM; Cook \& Kenny, 2005; Kenny et al., 2006). APIM was designed to deal with violations of statistical independence, as well as for investigating dyadic effects in close relationships. This model enables examining how an individual's predictor variable simultaneously and independently relates to his or her own criterion variable (actor effect) and to his or her partner's criterion variable (partner effect). We consider the dyad as the highest unit of analysis, with individuals nested within the dyad.

\section{Results}

\section{Preliminary Analyses}

The means, standard deviations, and correlations are presented in Table 1. First, to ensure that variables in this study are distinct from each other, we conducted a series of multilevel confirmatory factor analyses with Mplus 6.12 using ML estimator (Muthén \& Muthén, 2010). We compared a five-factor measurement model discriminating between the variables included in the study with a one-factor model with all the items loading on one single factor. Due to potential theoretical overlap, we also tested a four-factor measurement model in which surface acting at work and at home loaded on the same factor (four-factor Model 1). Similarly, we tested another four-factor measurement model in which exhaustion and emotional energy loaded on the same factor (four-factor Model 2). Results showed that the five-factor model fitted the data well, $\chi^{2}(128)=258.93$, $\mathrm{CFI}=.97, \mathrm{TLI}=.96, \mathrm{RMSEA}=.03, \mathrm{SRMR}$ (within) $=.04$ vs. SRMR (between) $=.10$. The chi-square difference test showed that the five-factor model fit much better to the data than (a) the one-factor model, $\Delta \chi^{2}(9)=3037.6$, $p<.001$ ); (b) the four-factor Model $1, \Delta \chi^{2}(7)=664.26$, $p<.001$, and (c) the four-factor Model 2, $\Delta \chi^{2}(7)=651.12$, $p<.001$. This indicates that the variables included in the study can be empirically discriminated from each other.

Furthermore, using Mplus, we found that although men and women only differed in the mean scores of some of the study variables (surface acting at work and exhaustion), there were no differences in variances and correlations between both genders, $\chi^{2}(120)=132.9$, $p>.05$. Thus, we decided to treat men and women as indistinguishable and control for gender in the subsequent analyses to take the mean differences into account. Additionally, number of children $(r=-.08$, $p<.05)$, and number of hours worked per week $(r=.07$, $p<.05)$ were associated with surface acting at home. Similarly, education was related to relationship satisfaction $(r=.08, p<.05)$. Therefore, these variables were used as covariates in the following analyses. 
Table 1. Mean, Standard Deviations, and Correlations

\begin{tabular}{|c|c|c|c|c|c|c|c|c|c|}
\hline Variable & $M(S D)$ & 1 & 2 & 3 & 4 & 5 & 6 & 7 & 8 \\
\hline 1. Surface acting at work, actor & $2.22(1.42)$ & - & & & & & & & \\
\hline 2. Exhaustion at work, actor & $3.37(1.47)$ & $.19^{* *}$ & - & & & & & & \\
\hline 3. Surface acting at home, actor & $1.49(0.92)$ & $.36^{* *}$ & $.12^{* *}$ & - & & & & & \\
\hline 4. Surface acting at home, partner & $1.49(0.92)$ & $.17^{*}$ & -.02 & $.30^{* *}$ & - & & & & \\
\hline 5. Emotional energy, actor & $4.17(1.35)$ & $-.11^{* *}$ & $-.17^{* *}$ & $-.22^{* *}$ & -.03 & - & & & \\
\hline 6. Emotional energy, partner & $4.17(1.35)$ & -.04 & -.03 & -.03 & $-.22^{* *}$ & $.28^{* *}$ & - & & \\
\hline 7. Relationship satisfaction, actor & $4.41(0.80)$ & $-.07^{*}$ & $-.14^{* *}$ & $-.29^{* *}$ & $-.17^{* *}$ & $.30^{* *}$ & $.22^{* *}$ & - & \\
\hline 8. Relationship satisfaction, partner & $4.41(0.80)$ & -.05 & $-.08^{*}$ & $-.17^{* *}$ & $-.29^{* *}$ & $.22^{* *}$ & $.30^{* *}$ & $.52^{* *}$ & - \\
\hline
\end{tabular}

Note. $N=80$ Dyads; $N=160$ Individuals; $N=800$ Observations.

$* p<.05 .{ }^{* *} p<.01$.

We also calculated whether our dependent variables exhibited sufficient between- and within-person variability. We calculated the intraclass correlations with the intercept-only model. ICC (1) is commonly referred to simply as the ICC in random coefficient models. Results indicated that the three-level model explained a significant amount of surface acting at home. Specifically, $51.99 \%$ of the variance could be attributed to within-person variations, $24.94 \%$ of the variance was attributable to between-person variations, and $23.07 \%$ of the variance was attributable to betweendyad variations. Regarding relationship satisfaction, results showed that $55.6 \%$ of the variance could be attributed to within-person variations, $5.7 \%$ of the variance was attributable to between-person variations, and $38.7 \%$ of the variance was attributable to betweendyad variations. Furthermore, a model with three levels showed a better fit to the data than a 2-level model (difference of $-2 \times \log =6.40, d f=1, p<.01$ ). Similarly, in the case of surface acting at home, a model with three levels showed a better fit to the data than a 2-level model (difference of $-2 \times \log =71.15, d f=1$, $p<.001)$. In light of these findings, the most appropriate strategy of analysis is the multilevel analysis, which takes into account the variation at these three levels (dyads, persons, days).

\section{Hypotheses Testing}

To test our study hypotheses, we examined a series of nested models. In the first model, predicting actor's surface acting at home, we included the intercept as the only predictor in the null model. In Model 1, we included the person-level control variables (gender, and worked hours per week) and the dyad-level control variable (number of children). In Model 2, we entered actor's surface acting at work. Finally, in Model 3, we entered actor's work-related exhaustion. We compared the model fit of these models by calculating the difference between the likelihood ratio of one model and the likelihood ratio of the previous one. This difference follows a chi-square distribution (with degrees of freedom being the number of variables added in each model). Model 3 showed a better fit to the data than Model 2 (difference of $-2 \times \log =4.59, d f=1, p<.05$ ), Model 1 (difference of $-2 \times \log =58.87, d f=2, p<.001$ ), and the null model (difference of $-2 X \log =247.56, d f=5$, $p<.001)$.

In the second model, predicting partner's relationship satisfaction, we included the intercept as the only predictor in the null model. In Model 1, we included the person-level control variables (gender, and educational level). In Model 2, we entered surface acting at home of both actor and partner. Finally, in Model 3, we entered emotional energy of both actor and partner. Model 3 showed a better fit to the data than Model 2 (difference of $-2 \times \log =71.85, d f=2, p<.001$ ), Model 1 (difference of $-2 \times \log =109.27, d f=4, p<.001$ ), and the null model (difference of $-2 \times \log =161.52, d f=6$, $p<.001$ ). Table 2 and 3 present unstandardized estimates, standard errors, and $t$ values for both models.

Hypothesis 1 suggests a mediating effect of actor's daily level of exhaustion on the relationship between daily actor's surface acting at work (SAW) and daily actor's surface acting at home (SAH). Note that this effect refers to the same individual- the intra-personal effect, also known as actor effect. After the inclusion of the mediator, the initial effect of SAW on SAH was reduced from $t=7.19(p<.001)$ to $t=6.88(p<.001)$. To ascertain whether this reduction was statistically significant, we followed recommendations by Preacher, Curran, and Bauer (2006) for testing mediation in multilevel models. We conducted a Monte Carlo simulation with 20,000 replications, and calculated the distribution of the mediation effect using the estimate and the standard error of the effect of the predictor $(x)$ on the mediator $(\mathrm{m})$, as well as the estimate and the standard error of $\mathrm{m}$ on the outcome variable (y). The Null hypothesis that $\mathrm{m}$ does not significantly mediate the relationship between $\mathrm{x}$ and $\mathrm{y}$ is rejected when the distribution of 
Table 2. Multilevel Estimates for Models Predicting Actor's Surface Acting at Home

\begin{tabular}{|c|c|c|c|c|c|c|c|c|c|c|c|c|}
\hline \multirow[b]{2}{*}{ Variable } & \multicolumn{3}{|c|}{ Null Model } & \multicolumn{3}{|l|}{ Model 1} & \multicolumn{3}{|l|}{ Model 2} & \multicolumn{3}{|l|}{ Model 3} \\
\hline & Estimate & $S E$ & $t$ & Estimate & $S E$ & $t$ & Estimate & $S E$ & $t$ & Estimate & $S E$ & $t$ \\
\hline Intercept & \multirow[t]{6}{*}{1.491} & \multirow[t]{6}{*}{0.066} & \multirow[t]{6}{*}{$22.5^{* * *}$} & 1.513 & 0.072 & $21.0^{* * *}$ & 1.506 & 0.061 & $24.6^{* * *}$ & 1.507 & 0.061 & $24.7^{* * *}$ \\
\hline Gender & & & & 0.058 & 0.104 & 0.55 & 0.143 & 0.093 & 1.53 & 0.162 & 0.091 & 1.78 \\
\hline Number of children & & & & -0.057 & 0.056 & -1.01 & -0.025 & 0.048 & -0.52 & -0.032 & 0.048 & -0.66 \\
\hline Worked hours per week & & & & 0.008 & 0.007 & 1.14 & 0.007 & 0.006 & 1.16 & 0.006 & 0.006 & 1.00 \\
\hline $\begin{array}{l}\text { Surface acting at work } \\
\text { (actor) }\end{array}$ & & & & & & & 0.187 & 0.026 & $7.19^{* * *}$ & 0.179 & 0.026 & $6.88^{* * *}$ \\
\hline $\begin{array}{l}\text { Work-related exhaustion } \\
\text { (actor) }\end{array}$ & & & & & & & & & & 0.052 & 0.024 & $2.16^{*}$ \\
\hline$-2 \times \log (\mathrm{lh})$ & \multirow{3}{*}{\multicolumn{3}{|c|}{$1,856.598$}} & \multicolumn{3}{|c|}{$1,667.903$} & \multicolumn{3}{|c|}{$1,613.625$} & \multicolumn{3}{|c|}{$1,609.033$} \\
\hline Difference of $-2 \times \log$ & & & & \multicolumn{3}{|c|}{$188.69^{* * *}$} & \multicolumn{3}{|c|}{$54.28^{* * *}$} & \multicolumn{3}{|c|}{$4.59^{*}$} \\
\hline$d f$ & & & & \multicolumn{3}{|c|}{3} & \multicolumn{3}{|c|}{1} & \multicolumn{3}{|c|}{1} \\
\hline $\begin{array}{l}\text { Level } 1 \text { intercept } \\
\text { variance }(S E)\end{array}$ & \multicolumn{3}{|c|}{$0.446(0.025)$} & \multicolumn{3}{|c|}{$0.464(0.028)$} & \multicolumn{3}{|c|}{$0.454(0.027)$} & \multicolumn{3}{|c|}{$0.452(0.027)$} \\
\hline $\begin{array}{l}\text { Level } 2 \text { intercept } \\
\text { variance }(S E)\end{array}$ & \multicolumn{3}{|c|}{$0.214(0.049)$} & \multicolumn{3}{|c|}{$0.238(0.057)$} & \multicolumn{3}{|c|}{$0.163(0.044)$} & \multicolumn{3}{|c|}{$0.158(0.043)$} \\
\hline $\begin{array}{l}\text { Level } 3 \text { intercept } \\
\quad \text { variance }(S E)\end{array}$ & \multicolumn{3}{|c|}{$0.198(0.061)$} & \multicolumn{3}{|c|}{$0.199(0.068)$} & \multicolumn{3}{|c|}{$0.137(0.050)$} & \multicolumn{3}{|c|}{$0.140(0.050)$} \\
\hline
\end{tabular}

Note. $N=80$ Dyads; $N=160$ Individuals $x 5$ days; $N=800$ Observations.

${ }^{*} p<.05 .{ }^{* *} p<.01 .{ }^{* * *} p<.001$.

possible estimates for $\mathrm{m}$ lies above or below zero. Results showed that actor's daily surface acting at work was positively related to actor's daily surface acting at home via daily work-related exhaustion. The Monte Carlo test showed that this mediating effect was significant since the biased corrected 95\% confidence interval did not include zero (lower bound [LB] $=.0021$, upper bound $[\mathrm{UB}]=.0127)$. Results suggest that there is a partial mediation effect. Thus, data tended to support Hypothesis 1.

To test Hypothesis 2, we followed the same procedure. Results showed that own daily SAH was negatively related to own daily relationship satisfaction via daily emotional energy. After the inclusion of the mediator, the initial effect of SAH on relationship satisfaction was reduced from $t=-5.46(p<.001)$ to $t=-4.43(p<.001)$. The Monte Carlo test showed that this effect was significant since the bias- corrected $95 \%$ confidence interval did not include zero (lower bound $[\mathrm{LB}]=.023$, upper bound $[\mathrm{UB}]=.052$ ). Therefore, partial mediation exists. Results support Hypothesis 2.

We also tested the mediating effect of daily emotional energy on the relationship between own's daily SAH to partner's daily relationship satisfaction. The mediating Hypothesis 2 was an intra-personal effect (actor effect), whereas the Hypothesis 3 was an interpersonal effect (partner effect). Results showed that the first condition of mediation, effect of IV on DV, was not significant. Actor's SAH was not related to partner's daily perception of relationship satisfaction $(\gamma=-0.016$, $S E=0.30, t=-0.53, p>.05)$. However, the Monte Carlo test showed that an indirect effect was significant since the bias- corrected 95\% confidence interval did not include zero (lower bound [LB] $=.009$, upper bound $[\mathrm{UB}]=.017)$. Thus, results suggest that there is a significant indirect effect. Indirect effects are a special form of intervening effects whereby the predictor and the dependent variable are not related directly, but they are indirectly related through significant relationships with a linking mechanism (Mathieu \& Taylor, 2006). Therefore, actor's SAH is related to partner's daily relationship satisfaction through actor's daily emotional energy. This means that Hypothesis 3 was partially supported.

\section{Discussion}

In the current study, we examined energy resources (i.e., work-related exhaustion and emotional energy) as underlying mechanisms explaining the spillover of surface acting from work to home, and the impact of surface acting at home on relationship satisfaction (as reported by both members of the couple). We contribute to the literature on emotional labor and the workfamily interface by showing that a loss spiral of energy resources explains the daily spillover and crossover of surface acting. We have examined energy resources as mediators in two different processes: spillover 
Table 3. Multilevel Estimates for Models Predicting Partner's Relationship Satisfaction

\begin{tabular}{|c|c|c|c|c|c|c|c|c|c|c|c|c|}
\hline \multirow[b]{2}{*}{ Variable } & \multicolumn{3}{|c|}{ Null Model } & \multicolumn{3}{|l|}{ Model 1} & \multicolumn{3}{|l|}{ Model 2} & \multicolumn{3}{|l|}{ Model 3} \\
\hline & Estimate & $S E$ & $t$ & Estimate & $S E$ & $t$ & Estimate & $S E$ & $t$ & Estimate & $S E$ & $t$ \\
\hline Intercept & 4.41 & 0.062 & $71.1^{* * *}$ & 4.413 & 0.062 & $71.7^{* * *}$ & 4.413 & 0.058 & $76.0^{* * *}$ & 4.414 & 0.056 & $78.8^{* * *}$ \\
\hline Gender & & & & 0.064 & 0.104 & 0.65 & 0.051 & 0.054 & 0.94 & 0.033 & 0.056 & 0.58 \\
\hline Level of education & & & & 0.018 & 0.020 & 0.90 & 0.017 & 0.020 & 0.85 & 0.014 & 0.021 & 0.66 \\
\hline $\begin{array}{c}\text { Surface acting at } \\
\text { home (actor) }\end{array}$ & & & & & & & -0.016 & 0.030 & -0.53 & -0.003 & 0.030 & -0.10 \\
\hline $\begin{array}{l}\text { Surface acting at } \\
\text { home (partner) }\end{array}$ & & & & & & & -0.164 & 0.030 & $-5.46^{* * *}$ & -0.133 & 0.030 & $-4.43^{* * *}$ \\
\hline $\begin{array}{l}\text { Emotional energy } \\
\quad \text { (actor) }\end{array}$ & & & & & & & & & & 0.105 & 0.023 & $4.56^{* * *}$ \\
\hline $\begin{array}{l}\text { Emotional energy } \\
\quad \text { (partner) }\end{array}$ & & & & & & & & & & 0.174 & 0.023 & $7.56^{* * *}$ \\
\hline$-2 \times \log (\mathrm{lh})$ & \multirow{3}{*}{\multicolumn{3}{|c|}{$1,683.860$}} & \multicolumn{3}{|c|}{$1,631.617$} & \multicolumn{3}{|c|}{$1,594.195$} & \multicolumn{3}{|c|}{$1,522.339$} \\
\hline Difference of $-2 \times \log$ & & & & \multicolumn{3}{|c|}{$52.24^{* * *}$} & \multicolumn{3}{|c|}{$37.42^{* * *}$} & \multicolumn{3}{|c|}{$71.85^{* * *}$} \\
\hline$d f$ & & & & \multicolumn{3}{|c|}{2} & \multicolumn{3}{|c|}{2} & \multicolumn{3}{|c|}{2} \\
\hline $\begin{array}{c}\text { Level } 1 \text { intercept } \\
\text { variance }(S E)\end{array}$ & \multicolumn{3}{|c|}{$0.362(0.020)$} & \multicolumn{3}{|c|}{$0.365(0.021)$} & \multicolumn{3}{|c|}{$0.357(0.020)$} & \multicolumn{3}{|c|}{$0.318(0.018)$} \\
\hline $\begin{array}{c}\text { Level } 2 \text { intercept } \\
\text { variance }(S E)\end{array}$ & \multicolumn{3}{|c|}{$0.036(0.018)$} & \multicolumn{3}{|c|}{$0.036(0.018)$} & \multicolumn{3}{|c|}{$0.037(0.018)$} & \multicolumn{3}{|c|}{$0.054(0.019)$} \\
\hline $\begin{array}{c}\text { Level } 3 \text { intercept } \\
\text { variance }(S E)\end{array}$ & \multicolumn{3}{|c|}{$0.252(0.050)$} & \multicolumn{3}{|c|}{$0.247(0.049)$} & \multicolumn{3}{|c|}{$0.207(0.043)$} & \multicolumn{3}{|c|}{$0.184(0.040)$} \\
\hline
\end{tabular}

Note. $N=80$ Dyads; $N=160$ Individuals $x 5$ days; $N=800$ Observations.

${ }^{*} p<.05 .{ }^{* *} p<.01 .{ }^{* * *} p<.001$.

and crossover. By including the work and the home domain, as well as the employee and the partner, we enhance our knowledge on life in and around organizations and around work. First, we focused on surface acting at work and proposed that this strategy would deplete energy resources, which in turn would increase surface acting at home. Previous evidence shows that having to express positive emotions when one does not feel them depletes resources (Grandey, Rupp, \& Brice, 2015), which may affect engagement in other areas of life. For example, when employees must fake expressions in response to emotion requirements, they have fewer resources available to engage in citizenship behavior (Trougakos, Beal, Cheng, Hideg, \& Zweig, 2015).

Our results show that surface acting spills over from work to home (direct effect, within-persons). This is in line with past research demonstrating the existence of a direct impact of surface acting at work and at home (Sanz-Vergel et al., 2012). As suggested by Edwards and Rothbard (2000), behaviors, mood and skills can be directly transferred from one domain to another domain. We go one step further and contribute to the work-family literature by providing evidence that work-related exhaustion partially explains the link between surface acting at work and at home. Our findings are in line with COR theory (Hobfoll, 1998,
2001), that states that people need to invest resources in order to gain more resources (Principle 2), but those with fewer resources are less capable of resource gain (Corollary 1). Energy resources like vitality/exhaustion are easily used up (Gorgievski, Halbesleben, \& Bakker, 2011). In our study, surface acting at work depleted energy resources, that is, employees were exhausted on the days they were "faking in bad faith" (Rafaeli \& Sutton, 1987). With fewer resources, employees cannot invest the energy needed for more elaborated emotion regulation strategies such as deep acting. Therefore, instead, they use surface acting also at home in order to adjust to family expectations. Thus, as individuals use up their energy at work, they correspondingly withdraw their investment of resources at home. The mediation is partial, which demonstrates that the relationship between surface acting at work and at home is indeed strong and does not totally disappear when we include exhaustion. Future studies should take into account other variables that may explain this link, and that are not related to energy (e.g., negative affect, quality of the interactions with the partner). It is also conceivable that the link between surface acting at work and at home is so strong that it will not easily disappear even when we include mediating variables. Sanz-Vergel et al. (2012) used Ashforth, Kreiner and Fugate's (2000) theory of micro-role transitions, and 
argued that the spillover of surface acting from work to family life is strong because people tend to behave similarly in both domains to make the daily role transitions easier. Another explanation may be that the direct transfer of behavior between work and family is likely when the situational cues (i.e., work and family requirements in the two domains) are similar (Edwards \& Rothbard, 2000, p. 187).

Second, we examined whether using surface acting at home had an effect on the satisfaction with the relationship (as reported by both, the employee and the partner) and proposed emotional energy in the evening as the explanatory variable (mediator). Before including the mediator, results showed that on days when employees used surface acting at home as a strategy to conform to family expectations, they were less satisfied with their partner. This is in line with previous studies showing the negative effects of emotional labor at home (Montgomery et al., 2005; Yanchus et al., 2010). When including the mediator, the relationship between surface acting at home and relationship satisfaction is significantly reduced although it does not disappear completely (partial mediation). Again, COR theory is able to explain this finding: People fake emotions and feel tired at home. As a result, resources are drained and individuals do not have enough energy left to interact with others. This means that they are lousy partners on these days -they are too tired to help in the household or to engage in social activities with the partner. This will undermine the satisfaction with the relationship on those days, because through social activities and combined effort in the household, the actor signals to the partner that he/she is worthwhile.

Another possible explanation for this mediating effect is that employees tend to evaluate the environment negatively when they have no energy. De Lange, Taris, Kompier, Houtman, and Bongers (2005) used this explanation, called "gloomy perception mechanism", to argue that unhealthy or tired employees tend to evaluate their environment more negatively and report less favorable work characteristics. We provide evidence that employees who report low emotional energy also evaluate their satisfaction with the partner less favorably, so the gloomy perception mechanism might affect not only the evaluation of work characteristics but also family-related outcomes.

Finally, we were unable to find a mediating effect of emotional energy in the relationship between surface acting at home and partner's ratings of relationship satisfaction. The first condition of the mediation was not met, as employees' surface acting at home did not affect the level of satisfaction reported by the partner. We consider there are two possible explanations for this finding. The use of surface acting at home may have an impact on the partner in the long-term but not on a daily basis. If the employee fakes emotions but conforms to family expectations, the level of partner's satisfaction that day is not affected. Longitudinal studies could help to elucidate whether using surface acting at home affects family life over time. A second plausible explanation is that surface acting at home affects other aspects not related to satisfaction (e.g., negative affect). There could also be some variables intervening in this process. For example, previous studies have shown that surface acting involves inauthentic emotional displays, which might lead to negative reactions from interaction partners (Grandey, 2003). In the present study, we have not measured whether the partner actually realized that the employee was faking. It may be that surface acting at home leads to partner's lower satisfaction under specific conditions (e.g., when the partner realizes that the employee is faking emotions).

However, it is worth mentioning that there was an indirect effect, because employee's surface acting at home was related to emotional energy, and emotional energy was significantly related to partner's satisfaction with the relationship. This is a crossover effect showing that on days when employees have no energy left to interact with others, their partner is not satisfied. Therefore, when employees enter into a vicious cycle of daily resource loss, they are not only reducing their chances to gain more resources but they are also making their partner lose resources (i.e., they are less satisfied with the relationship which means they lose "social resources"). Taken together, our results provide evidence for a loss spiral that impedes employees break the vicious cycle and use more appropriate strategies to deal with family emotional requirements. This affects not only their own but also their partner's level of satisfaction with the relationship. Employees need to learn emotional regulation strategies that do not deplete their resources, as this will enable them to use more elaborated strategies both at work and at home, avoiding entering into a vicious cycle affecting their well-being and their family life.

In spite of the large number of observations, the high response rate, and the data collection of dyads at multiple points in time, our study had some limitations. First, we used a convenience sample, which may limit the generalizability of our findings. However, we consider that this does not threaten the validity of our results. Although we studied mechanisms at the withinperson level, we have no reason to believe that these mechanisms will be different in other samples. Other cross-sectional and daily studies on emotional labor had samples with similar characteristics in terms of age, number of children or the number of working hours (Martínez-Íñigo et al., 2007; Montgomery et al., 2005; Sanz-Vergel et al., 2012; Yanchus et al., 2010). The main issue with some of these studies was that they 
did not include a variety of occupational sectors as we have or they did not have a balanced sample in terms of gender (Montgomery et al., 2005; Yanchus et al., 2010). We consider that our particular sample is not problematic because we have the same percentage of women and men and we have different occupational sectors. However, as we had a higher percentage of people working in the health sector as compared to other sectors, we call for more research on this topic to generalize our results. In sum, future studies should explore the spillover and crossover of emotional labor using representative samples (e.g., people working in shifts or employees reporting a higher/lower number of working hours per week).

Second, we used paper booklets, so we cannot ensure that the timing of report was accurate. However, we tried to maximize compliance and timely completion through several actions. We included a detailed explanation concerning the aims of the study and the utility of accurate responding. Furthermore, we did not use monetary incentives which significantly reduces the problem of faked responses and backdated entries (Green, Rafaeli, Bolger, Shrout, \& Reis, 2006; Ohly et al., 2010). In the booklet, we included a space where the participants had to indicate the specific time in which they were filling in the diary (both in the afternoon and in the evening). We did not include questionnaires that were not completed each day during the study period, or where the reported time was not appropriate (e.g., participants filling in the questionnaire at the end of the day instead of twice: Time 1: afternoon, Time 2: evening). On average, participants completed afternoon surveys at 18:27 ( $S D=2.04 \mathrm{hr})$, and evening surveys at $23.46(S D=1.38 \mathrm{hr})$. Future studies may use electronic devices to avoid this problem.

Finally, another limitation of the present study is that we assessed relationship satisfaction using a single-item measure. Although single-item measures have been criticized, considerable research has indicated that single-item measures of affective states are strongly correlated with multiple-item measures of the same concept (e.g., Fisher et al., 2016), suggesting they can be valid. However, as single-item measures are likely to attenuate relationships between variables, future studies could use multi-item scales measures with a broader coverage of the construct to gain insight into different facets of relationship satisfaction.

Despite these limitations, the present findings suggest that emotional labor has ripple effects, which has important implications for practice. Organizations should be aware of the detrimental consequences of surface acting and try to minimize employee's daily exposition to emotional stressors. For example, job crafting in the form of reducing emotional demands or increasing social resources, may help employees maintain their well-being. In addition, organizations should offer training on how to deal with emotional demands, such as training on emotion regulation strategies. For example, the use of deep acting or "natural and genuine emotional labor" results in positive outcomes, so there is a "bright side of emotional labor" (Humphrey, Ashforth, \& Diefendorff, 2015). Learning these strategies will be helpful to better cope with emotional demands not only at work but also at home. Our study demonstrates that surface acting may be used in both domains, so if employees learn more "positive" strategies at work, they may be able to use them also at home. This would be a form of "work-family facilitation", that is, skills learned at work are useful to deal with family issues (Greenhaus \& Powell, 2006). Deep acting may result in energy resources that help to gain future resources, instead of entering into a loss spiral of energy resources. The efficacy of training interventions on emotion regulation strategies has mainly been tested in the field of Clinical Psychology and there is evidence that this type of intervention has positive effects on mental health (Berking et al., 2008). These interventions could include training on problem-solving, effective re-appraisal, empathy or mindfulness.

Finally, research has shown that disconnecting from work and engaging in non-work related tasks (e.g., relaxing activities) during leisure time, increase wellbeing (Sonnentag \& Fritz, 2007). From this point of view, using surface acting at home will be less likely if employees disengage from their work-related mood and reconnect with their family. Organizations can also help employees make the micro-transition from work to home easier by offering training programs on how to better recover from work-related stress. There is evidence that this type of training increases employees' recovery-related self-efficacy and well-being (Hahn, Binnewies, Sonnentag, \& Mojza, 2011). We suggest that a combination of such practices can help employees to keep a positive balance between both life domains.

\section{References}

Ashforth B. E., Kreiner G. E., \& Fugate M. (2000). All in a day's work: Boundaries and micro role transitions. Academy of Management Review, 25, 472-491. https:/ / doi. org/10.5465/amr.2000.3363315

Berking M., Wupperman P., Reichardt A., Pejic T., Dippel A., \& Znoj H. (2008). Emotion-regulation skills as a treatment target in psychotherapy. Behaviour Research and Therapy, 46(11), 1230-1237. https:/ / doi. org/10.1016/j.brat.2008.08.005

Brotheridge C. M., \& Lee R. T. (2003). Development and validation of the Emotional Labor scale. Journal of Occupational and Organizational Psychology, 76, 365-379. https:/ / doi.org/10.1348/096317903769647229

Cook W. L., \& Kenny D. A. (2005). The Actor-Partner Interdependence Model: A model of bidirectional effects 
in developmental studies. International Journal of Behavioral Development, 29, 101-109. https://doi. org /10.1080/01650250444000405

de Lange A. H., Taris T. W., Kompier M. A. J., Houtman I. L. D., \& Bongers P. M. (2005). Different mechanisms to explain the reversed effects of mental health on work characteristics. Scandinavian Journal of Work, Environment \& Health, 31, 3-14. https:/ / doi. org/10.5271/sjweh.843

Demerouti E., \& Rispens S. (2014). Improving the image of student-recruited samples: A commentary. Journal of Occupational and Organizational Psychology, 87(1), 34-41. https:/ / doi.org/10.1111/joop.12048

Demerouti E., Bakker A. B., \& Schaufeli W. B. (2005). Spillover and crossover of exhaustion and life satisfaction among dual-earner parents. Journal of Vocational Behavior, 67, 266-289. https://doi.org/10.1016/j.jvb.2004.07.001

Edwards J. R., \& Rothbard N. P. (2000). Mechanisms linking work and family: Clarifying the relationship between work and family constructs. Academy of Management Review, 25(1), 178-199. https://doi.org/10.5465/amr.2000.2791609

Fisher G. G., Matthews R. A., \& Gibbons A. M. (2016). Developing and investigating the use of single-item measures in organizational research. Journal of Occupational Health Psychology, 21(1), 3-23. https://doi.org/10.1037/ a0039139

Gorgievski M. J., Halbesleben J. R. B., \& Bakker A. B. (2011). Expanding the boundaries of psychological resource theories. Journal of Occupational and Organizational Psychology, 84(1), 1-7. https://doi.org/10.1111/j.2044-8325. 2010.02015.x

Grandey A. A. (2000). Emotion regulation in the workplace: A new way to conceptualize emotional labor. Journal of Occupational Health Psychology, 5, 95-110. https:/ / doi. org/10.1037//1076-8998.5.1.95

Grandey A. A. (2003). When 'the show must go on:' Surface acting and deep acting as determinants of emotional exhaustion and peer-rated service delivery. Academy of Management Journal, 46, 86-96. https:/ / doi. org / 10.5465/30040678

Grandey A. A., \& Gabriel A. S. (2015). Emotional labor at a crossroads: Where do we go from here? Annual Review of Organizational Psychology and Organizational Behavior, 2, 323-349. https://doi.org/10.1146/annurev-orgpsych032414-111400

Grandey A. A., Rupp D., \& Brice W. N. (2015). Emotional labor threatens decent work: A proposal to eradicate emotional display rules. Journal of Organizational Behavior, 36, 770-785. https://doi.org/10.1002/job.2020

Green A. S., Rafaeli E., Bolger N., Shrout P. E., \& Reis H. T. (2006). Paper or plastic? Data equivalence in paper and electronic diaries. Psychological Methods, 11, 87-105. https://doi.org/10.1037/1082-989X.11.1.87

Greenhaus J. H., \& Powell G. N. (2006). When work and family are allies: A theory of work-family enrichment. Academy of Management Review, 31(1), 72-92. https: / / doi. org/10.5465/AMR.2006.19379625

Hahn V. C., Binnewies C., Sonnentag S., \& Mojza E. J. (2011). Learning how to recover from job stress: Effects of a recovery training program on recovery, recovery-related self-efficacy, and well-being. Journal of Occupational Health Psychology, 16, 202-216. https:/ / doi.org/10.1037/ a0022169

Halbesleben J. R. B., Harvey J., \& Bolino M. C. (2009). Too engaged? A conservation of resources view of the relationship between work engagement and work interference with family. Journal of Applied Psychology, 94(6), 1452-1465. https://doi.org/10.1037/a0017595

Humphrey R. H., Ashforth B. E., \& Diefendorff J. M. (2015). The bright side of emotional labor. Journal of Organizational Behavior, 36(6), 749-769. https:/ / doi. org/10.1002/job.2019

Hennig-Thurau T., Groth M., Paul M., \& Gremler D. D. (2006). Are all smiles created equal? How emotional contagion and emotional labor affect service relationships. Journal of Marketing, 70, 58-73. https:/ / doi.org/10.1509/jmkg.70.3.58

Hobfoll S. E. (1998). Stress, culture, and community: The psychology and physiology of stress. New York, NY: Plenum Press.

Hobfoll S. E. (2001). The influence of culture, community, and the nested-self in the stress process: Advancing conservation of resources theory. Applied Psychology, 50(3), 337-421. https:/ / doi.org/10.1111/1464-0597.00062

Hobfoll S. E., \& Shirom A. (2001). Conservation of resources theory: Applications to stress and management in the workplace. In R. T. Golembiewski (Ed.), Handbook of organizational behavior (pp. 57-81). New York, NY: Dekker.

Hochschild A. R. (1983). The managed heart: Commercialization of human feeling. Berkeley, CA: University of California Press.

Hoobler J. M., \& Brass D. J. (2006). Abusive supervision and family undermining as displaced aggression. Journal of Applied Psychology, 91, 1125-1133. https:/ / doi. org/10.1037/0021-9010.91.5.1125

Hülsheger U. R., \& Schewe A. F. (2011). On the costs and benefits of emotional labor: A meta-analysis of three decades of research. Journal of Occupational Health Psychology, 16, 361-389. https:/ / doi.org/10.1037/a0022876

Ilies R., Nahrgang J. D., \& Morgeson F. P. (2007). Leader-member exchange and citizenship behaviors: A meta-analysis. Journal of Applied Psychology, 92(1), 269-277. https: / / doi.org/10.1037/0021-9010.92.1.269

Judge T. A., Woolf E. F., \& Hurst C. (2009). Is emotional labor more difficult for some than for others? A multilevel experience-sampling study. Personnel Psychology, 62, 57-88. https://doi.org/10.1111/j.1744-6570.2008.01129.x

Kenny D. A., Kashy D. A., \& Cook W. L. (2006). Dyadic data analysis. New York, NY: The Guilford Press.

Kunin T. (1955). The construction of a new type of attitude measure. Personnel Psychology, 8, 65-77. https://doi. org/10.1111/j.1744-6570.1955.tb01189.x

Martínez-Íñigo D., Totterdell P., Alcover C. M., \& Holman D. (2007). Emotional labor and emotional exhaustion: Interpersonal and intrapersonal mechanisms. Work \& Stress, 21, 30-47. https:/ / doi. org /10.1080/02678370701234274

Mathieu J. E., \& Taylor S. R. (2006). Clarifying conditions and decision points for meditational type inferences in organizational behavior. Journal of Organizational Behavior, 27, 1031-1056. https://doi.org/10.1002/job.406 
Montgomery A. J., Panagopolou E., \& Benos A. (2005). Emotional labor at work and at home among Greek health-care professionals. Journal of Health Organization and Management, 19, 395-409. https://doi.org/10.1108/ 14777260510615413

Muthén L. K., \& Muthén B. O. (2010). Mplus. Statistical Analysis with Latent Variables. User's guide. Los Angeles, CA: Muthén \& Muthén.

Ohly S., Sonnentag S., Niessen C., \& Zapf D. (2010). Diary studies in organizational research: An introduction and some practical recommendations. Journal of Personnel Psychology, 9, 79-93. https://doi.org/10.1027/1866-5888/ a000009

Philipp A., \& Schüpbach H. (2010). Longitudinal effects of emotional labor on emotional exhaustion and dedication of teachers. Journal of Occupational Health Psychology, 15(4), 494-504. https://doi.org/10.1037/a0021046

Preacher K. J., Curran P. J., \& Bauer D. J. (2006). Computational tools for probing interaction effects in multiple linear regression, multilevel modeling, and latent curve analysis. Journal of Educational and Behavioral Statistics, 31, 437-448. https: / / doi. org/10.3102/10769986031004437

Rafaeli A., \& Sutton R. I. (1987). Expression of emotion as part of the work role. Academy of Management Review, 12(1), 23-37. https://doi.org/10.2307/257991

Rasbash J., Browne W., Healy M., Cameron B., \& Charlton C. (2002). MLwiN (Version 1.10.006) [Interactive software for multilevel analysis]. London, UK: Centre for Multilevel Modelling, Institute of Education, University of London.

Sanz-Vergel A. I., Rodríguez-Muñoz A., Bakker A. B., \& Demerouti E. (2012). The daily spillover and crossover of emotional labor: Faking emotions at work and at home.
Journal of Vocational Behavior, 81, 209-217. https:/ / doi. org/10.1016/j.jvb.2012.07.003

Shirom A. \& Melamed S. (2006). A comparison of the construct validity of two burnout measures in two groups of professionals. International Journal of Stress Management, 13, 176-200. https://doi.org/10.1037/10725245.13.2.176

Shirom A. (2004). Feeling vigorous at work? The construct of vigor and the study of positive affect in organizations. In D. Ganster \& P. L. Perrewe (Eds.), Research in organizational stress and well-being (pp. 135-165). Greenwich, CT: JAI Press.

Sonnentag S., \& Fritz C. (2007). The Recovery Experience Questionnaire: Development and validation of a measure for assessing recuperation and unwinding from work. Journal of Occupational Health Psychology, 12, 204-221. https://doi.org/10.1037/1076-8998.12.3.204

Totterdell P., \& Holman D. (2003). Emotion regulation in customer service roles: Testing a model of emotional labor. Journal of Occupational Health Psychology, 8, 55-73. https:/ / doi.org/10.1037/1076-8998.8.1.55

Trougakos J. P., Beal D. J., Cheng B. H., Hideg I., \& Zweig D. (2015). Too drained to help: A resource depletion perspective on daily interpersonal citizenship behaviors. Journal of Applied Psychology, 100(1), 227-236. https://doi. org $/ 10.1037 / \mathrm{a} 0038082$

Westman M. (2001). Stress and strain crossover. Human Relations, 54, 717-751. https:/ / doi. org/10.1177/0018726701546002

Yanchus N. J., Eby L. T., Lance C. E., \& Drollinger S. (2010). The impact of emotional labor on work-family outcomes. Journal of Vocational Behavior, 76, 105-117. https: / doi. org/10.1016/j.jvb.2009.05.001 